\title{
Migratory Reductive Cross-Coupling via Dual Nickel Metathesis
}

\author{
Yuqiang Li, Binzhi Zhao, Long Peng, Guoyin Yin
}

Submitted date: 17/05/2020 Posted date: 19/05/2020

Licence: CC BY-NC-ND 4.0

Citation information: Li, Yuqiang; Zhao, Binzhi; Peng, Long; Yin, Guoyin (2020): Migratory Reductive Cross-Coupling via Dual Nickel Metathesis. ChemRxiv. Preprint. https://doi.org/10.26434/chemrxiv.12318398.v1

Cross-electrophile coupling has been developed into a practical approach for the construction of carbon-carbon bonds, wherein nickel catalysis has been widely employed. Mechanistically, a catalytic cycle involvingsequentially selective oxidative addition or radical chain process is proposed. Although the catalytic cycle of dual nickel metathesis has been discussed in several important works, none thinks this pathway is possible. In this manuscript, we present a thorough mechanistic study by a series of designed experiments toward the nickel-catalyzed migratory reductive cross-coupling. The results suggest that a catalytic cycle involving two organonickel(II) species metathesis as a key step, operates in this reaction. Moreover, we provide a discussion on the difference between the nickel-catalyzed migratory reductive cross-couplings and the classical ones. Additionally, based on the mechanistic finding, a new catalytic system has also been developed, which allows the use of electron-deficient aryl halides as starting materials, affording the migratory cross-coupling products efficiently.

File list (3)

Manuscript.pdf (2.27 MiB) view on ChemRxiv • download file Supplementary Figure.pdf (433.71 KiB) view on ChemRxiv • download file 


\section{Other files}

Manuscript.pdf (2.27 MiB)

Supplementary Figure.pdf (433.71 KiB)

Supplementary Information.pdf (6.33 MiB) view on ChemRxiv • download file view on ChemRxiv - download file view on ChemRxiv • download file 